\title{
Abertura: uma questão, um caminho, uma viagem
}

\author{
Ricardo Trevisan
}

\section{SciELO Books / SciELO Livros / SciELO Libros}

TREVISA, R. Abertura: uma questão, um caminho, uma viagem. In: Cidades novas [online]. Brasília: Editora UnB, 2020, pp. 19-35. Pesquisa, inovação \& ousadia series. ISBN: 978-65-5846-158-6.

https://doi.org/10.7476/9786558461586.0003.

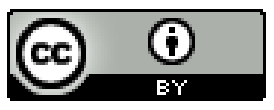

All the contents of this work, except where otherwise noted, is licensed under a $\underline{\text { Creative }}$ Commons Attribution 4.0 International license.

Todo o conteúdo deste trabalho, exceto quando houver ressalva, é publicado sob a licença Creative Commons Atribição 4.0.

Todo el contenido de esta obra, excepto donde se indique lo contrario, está bajo licencia de la licencia Creative Commons Reconocimento 4.0. 


\section{Abertura: uma questão, um caminho, uma viagem}

Paris, 3 de julho de 2008.

Manhã pouco ensolarada, de temperatura agradável para um dia de verão na capital francesa. Igualmente agradável para a primeira visita a uma cidade nova na região da Grande Paris, Évry.

Parto da Cité Universitaire às 9h30 da manhã. Na estação do trem suburbano (RER), a compra do bilhete de ida e volta me proporciona uma surpresa inicial. No guichê, meu destino, a estação de Évry-Courcourrone, faz os funcionários da RATP me olharem espantados. “O que um estrangeiro vai fazer em Évry?”, devem ter pensado. Percebi que a situação era merecedora de explicação. Como resposta, relatei que estudo cidades novas, as francesas villes nouvelles, e que a viagem seria necessária para minhas pesquisas. Entre a efetuação da compra e a emissão dos bilhetes, não posso deixar de ouvir algumas passagens do diálogo entres eles: "Fazer o quê numa cidade de interior?” ou “Ah, é aquela cidade onde as pessoas saem para trabalhar em Paris”. Após esse primeiro contato com meu objeto de análise e pagar € 9,90 pela passagem, sigo para a plataforma. Itinerário: RER B rumo à estação Châtelet; de lá, tomo o metrô da linha 14 até Gare de Lyon, onde encontro a arquiteta Renata Ralid, companheira nessa aventura e amiga dos tempos de faculdade na USP de São Carlos.

Um café à espera do RER D, que nunca chegou por problemas de circulação. A alternativa: pegar um trem da SNCF (grandes lignes) na plataforma "L”, rumo ao sudeste da região metropolitana, parando em inúmeras estações pelo caminho. Uns 40 minutos depois, chegamos a Évry. Nos primeiros 15 minutos da viagem, tinha-se a presença da mancha urbana contínua, com bairros residenciais de baixa densidade, algumas torres habitacionais aqui e acolá, uma infinidade de galpões 
industriais entremeados por desmanches de carros, por vezes um novo centro de bairro, mais uma estação, mais uma partida. Aos poucos, os espaços cinzentos ao longo da via férrea iam sendo substituídos por campinas: era a presença da campagne, da natureza, começando a se sobressair entre as construções urbanas.

Chegamos à estação de Évry-Courcourrone/Préfecture por volta das $11 \mathrm{~h} 10$. Diferentemente das estações anteriores (plataformas simples, em superfície, de estruturas metálicas), essa estação é uma caixa de concreto semienterrada, com pé-direito alto, escadas rolantes e um número significativo de usuários. De pronto, percebi que estávamos num centro urbano diferenciado. Subimos ao pavimento térreo, onde nos deparamos com duas alternativas de saída: Agora (Ágora) e Théâtre (Teatro) do lado esquerdo ou Cathédral (Matriz) e Mairie (Prefeitura) do lado direito. Como a vista de dentro da gare favorecia a paisagem à direita, tendo a surpreendente igreja do arquiteto suíço Mario Botta como ponto focal, seguimos por essa saída.

A princípio, é uma cidade feita de tijolos. Não apenas a igreja com pedigree, mas com a maioria dos prédios ao seu redor expondo, em suas fachadas, um tijolo vermelho contrastante com o céu azul semiencoberto. A entrada da estação ficou para trás; à nossa frente, a Praça das Nações. Uma esplanada pontuada por árvores e cortada por fontes d’água. Em seu contorno, a igreja matriz, centralizada, ladeada por duas edificações multifuncionais: à direita, um edifício de serviços e comércios; à esquerda, a sede da administração municipal.

Após uma rápida visita à igreja - de 800 mil tijolos, com iluminação zenital e coroada por 24 árvores -, entramos na prefeitura em busca de material para a pesquisa. Conseguimos apenas o mapa da cidade, indispensável num ambiente desconhecido.

Nele, observo que as vias em branco são para veículos e em amarelo para pedestres, quase sempre dissociadas, indício da influência do urbanismo funcionalista na concepção da cidade. Ademais, os edifícios vistos inicialmente, dispostos regularmente face às ruas e avenidas, haviam cedido lugar para edifícios distribuídos irregularmente. E não somente uma implantação irregular, mas também uma composição volumétrica diferenciada. Não estávamos numa cidade tradicional. 
Identifiquei duas causas para tal percepção: a ausência, típica em cidades modernistas, do parcelamento do solo em lotes; e, como consequência, a presença de quarteirões delimitados por vias veiculares e permeados por caminhos para pedestres.

Tal disposição gerou aquilo que denominei de uma desordem voluntária e consciente. Não uma desordem espontânea, como aquela de cidades convencionais, mas uma tentativa artificial de dispor os edifícios de modo irregular, de desordená-los segundo uma lógica própria, um partido ideológico-conceitual específico.

Se, por um lado, essa desordem voluntária e consciente favoreceu o surgimento de inúmeros espaços públicos, além de uma variedade de percursos para pedestres, por outro, gerou inúmeros espaços residuais, locais de baixa qualidade espacial quanto ao uso, ermos, sem cuidados, “espaços cegos”, diria o urbanista Frederico de Holanda.

A caminho da Ágora, a calçada, no nível térreo, se transforma em escadarias. A partir daí, nosso deslocamento será num pavimento superior, por passarelas ziguezagueantes. Tal separação entre pedestres e veículos pode ser positiva em áreas estritamente residenciais - como nas unidades de vizinhança americanas ou nas superquadras brasilienses e seus passeios seguros para crianças -, mas em Évry, sua adoção nas áreas centrais de maior caráter comercial resultou, a meu ver, negativa. Por que distanciar aquele que passa de automóvel, potencial consumidor, dos serviços prestados na região? A contragosto, as vias centrais assumem a função única de circulação veicular. Suas vitrines e placas indicativas dos serviços ofertados foram realocadas para um nível superior, para um espaço privatizado, a Ágora.

Ah, a Ágora! Pasmo fiquei ao perceber que o seu conceito original - uma praça com acesso livre e atividades diversas - havia se transformado numa galeria comercial, num shopping center. Embora abrigando equipamentos culturais e esportivos em seu interior (convívio, teatro e piscina), seu usuário é obrigado a adentrar o edifício para acessá-los. O espaço público das ruas comerciais perdeu seu posto para o espaço privado, com suas redes de restaurantes fast-food, suas lojas padronizadas, seus corredores herméticos e seus vigilantes sempre atentos. 
Uma parada para o almoço. Momento em que percebemos uma diferença de comportamento nos habitantes de Évry: eles são mais gentis que os parisienses, algo típico de cidades do interior!

Ao sair daquele centro enclausurado, verifiquei que a arquitetura de tijolos havia se dissipado, substituída por edifícios com arquitetura peculiar à época de criação da cidade, os anos 1970. Um exemplo é a Préfecture, sede administrativa do Departamento da Região de Essone. Um complexo de edifícios em barra, com empenas de concreto aparente e fachadas envidraçadas, isolados por amplos espelhos d'água. Algo destoante do restante da cidade: uma superquadra e seu superbloco!

Vamos em direção ao bairro denominado Les Pyramides (As Pirâmides), o percurso feito sempre acima das ruas de Évry, por passarelas ou edifícios-pontes. Ao passar por uma delas, outra superquadra e sua arquitetura, dessa vez residencial. Encontram-se ali edifícios habitacionais de até oito pavimentos, térreos reservados a salas comerciais ou de serviços - em grande parte abandonadas -, circundando um amplo pátio interno arborizado de livre acesso, algo semelhante às superquadras brasilienses, porém sem a mesma fluidez visual au rez-de-chaussée.

Prosseguindo em nossa promenade, um edifício com fachadas multifacetadas em vidro espelhado num tom amarelado chamou minha atenção por suas funções. Trata-se de um complexo multifuncional, com serviços e comércio no nível superior, onde nos encontrávamos, e terminal de ônibus urbano no nível inferior (vias). Os espaços que surgiam entre as partes desse edifício se transformaram em singelos belvederes, com vista para espelhos d’água e para Les Pyramides.

Clara ficou a origem do nome: prédios escalonados, zigurates, com um gabarito de até oito pavimentos. De relance, eles apresentam boas condições, tendo a maioria de suas varandas ajardinadas - quiçá uma referência aos Jardins Suspensos da Babilônia! Todavia, ao atravessar uma passarela à la Santiago Calatrava, chegamos numa superquadra também de pirâmides, porém em situação oposta às primeiras. A precariedade da manutenção das edificações, ocupadas por classes sociais de menor poder econômico, era perceptível nos balcões abandonados ou servindo de depósito para quinquilharias, 
no comércio fechado, nas portarias depredadas, nas fachadas deterioradas. O ponto positivo encontrado foi a presença de inúmeros equipamentos - creche, biblioteca, escola, playgrounds etc. - em boas condições e sendo utilizados pela população local.

Figura 1: Les Pyramides

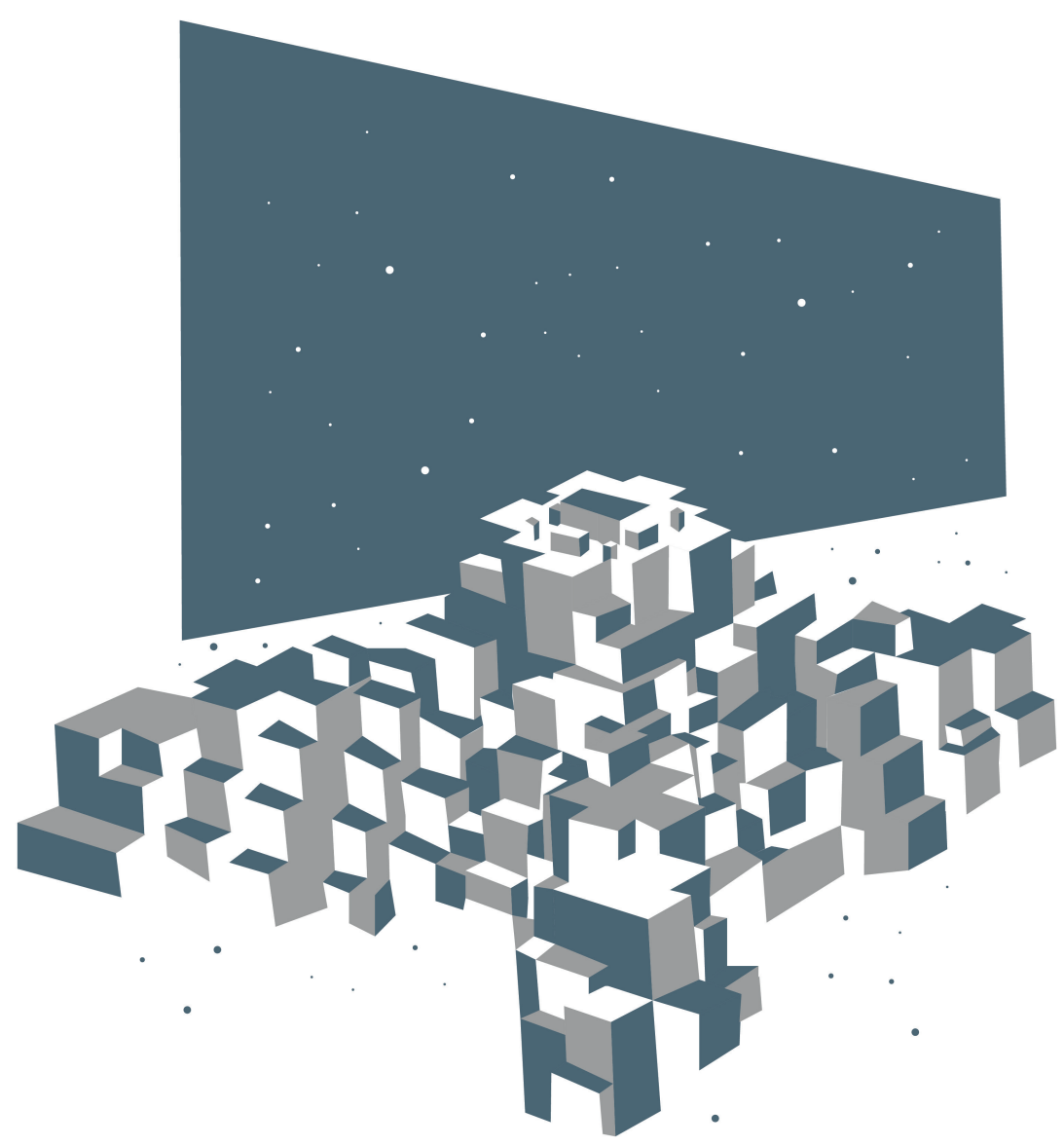


À medida que caminhávamos rumo aos limites da cidade, ficou óbvio que a densidade diminuía. Os edifícios ficavam mais distantes entre si, levando a uma maior área de vazios, além de seu gabarito baixar para três e dois pavimentos. A forma piramidal, sempre constante na paisagem do bairro, era por vezes interrompida pela presença de alguns prédios em barra ou por pequenas torres de arquitetura experimental.

Os limites da cidade, nessa direção, são nitidamente traçados por avenidas largas com trânsito intenso. Chegara o momento de retornar ao centro. Caminho diferente ao da vinda, a volta nos revelou mais pirâmides e pequenas praças. Descobri algumas curiosidades, como a varanda de área quadrada, que foi dividida ao meio por uma parede de tijolos disposta diagonalmente. Ao separar o espaço em duas áreas externas de apartamentos distintos, o objetivo da obra pós-ocupação foi a privatização do terraço compartilhado.

Chegamos ao Centro Comercial, simples continuação da Ágora, porém com uma fachada mais ostentosa, elemento que faltava para configurá-lo como um verdadeiro mall! Além do cenário familiar, a constatação dos estacionamentos horizontais e verticais repletos de carros indicava duas possibilidades: ou o shopping estava abarrotado de gente (e garanto que não estava) ou os proprietários desses veículos utilizavam desse serviço para acessar a estação de trem rumo a Paris (fico com esta opção). Indícios de uma cidade-dormitório.

Ao deixar o Centro Comercial pela Ágora, nos deparamos com uma placa indicativa para a estação de Évry-Courcourrone/Préfecture. Não era o caminho que havíamos feito de início. Menos convidativo, optamos por segui-lo. O fluxo de pedestres é intenso. O trajeto começa por uma rampa de veículos ladeada por estreitas calçadas. Dessa rampa, continua-se por uma rua sinuosa, delimitada por um muro cego e pelas saídas de serviço dos prédios. Ao final, aproximadamente 200 metros depois da Ágora, se encontra a outra entrada da estação, aquela rejeitada por nós na chegada. A estreita rua de serviços é o espaço mais vivo e menos qualificado ambientalmente da cidade! Embora as condições físicas não caracterizem esse percurso como deveriam de fato, sendo a rua com maior trânsito de pessoas, 
entendi que seu uso intenso acontece por ser a ligação mais curta entre o Centro Comercial e a estação, ou melhor, entre o edifício-garagem e a estação.

Às 16h terminamos nossa deriva. Entramos na grande estrutura em concreto da estação em direção a Paris.

Attention à la marche en descendant du train...

Do caminho, a cidade.

(Henri Lefebvre, O direito à cidade, 1969 apud Panerai, 2006, p. 17).

Agradeço a todos por terem embarcado, sem consulta prévia, nessa breve viagem à cidade nova de Évry. Pela narrativa, pudemos vivenciar juntos a atmosfera que compõe essa cidade-satélite localizada nos arredores parisienses. Ao listar suas qualidades, encontramos, dentre outras, sua interligação com a cidade-mãe (Paris) pelo transporte ferroviário, de fácil acesso e com fluxo constante; sua arquitetura inusitada e experimental; suas funções centrais repaginadas (Ágora); seu urbanismo modernista; seu traçado diferenciado; suas superquadras com seus superblocos; seus espaços públicos diversificados; sua população educada e solícita; sua dependência de Paris. Uma cidade criada há 50 anos pelo governo francês para controle ordenado do crescimento da metrópole sobre um sítio previamente escolhido e produto das teorias arquitetônicas e urbanísticas em voga. Uma Cidade Nova.

Escolhi Évry, mas poderia ter sido qualquer outra, de semelhante origem, para introduzir o presente livro. Um chamariz para convidá-los a me acompanharem numa outra viagem, de maior importância. Trata-se de uma viagem conceitual, conduzida pela história e por teorias urbanas, passando por outras cidades novas no Brasil e no mundo, da Antiguidade ao presente. Uma viagem desbravadora, tendo como destino a essência que compõe essa personagem pouco explorada na urbanística brasileira. 
Identifico-me, para aqueles que se aventurarem, como perseverante pesquisador da temática Cidades Novas, daqui por diante CNs. Desde 1997, ainda graduando no Departamento de Arquitetura e Urbanismo da Escola de Engenharia de São Carlos da Universidade de São Paulo, entrei para o grupo de pesquisa Pioneiros da Habitação Social no Brasil, coordenado pelos professores Nabil George Bonduki, Sarah Feldman e Carlos Roberto Monteiro de Andrade. Como bolsista da Fapesp, iniciei um trabalho intitulado “Cidades novas de colonização e expansão territorial no Noroeste do estado de São Paulo (1930-1964)”. Em um ano de leituras, levantamentos, visitas in loco, sistematização de materiais, elaboração de relatórios, aproximei-me do universo de 42 CNs paulistas, das quais 12 foram escolhidas para uma análise mais detalhada de sua história e projeto. Além dessa, outras pesquisas no grupo tiveram como foco CNs implantadas no norte do estado do Paraná, assim como cidades empresariais paulistas. Ao final do projeto, conseguimos compreender o processo de ocupação e a formação da rede urbana nessa região do país atualmente tão próspera.

Os estudos prosseguiram, a partir de 2001, no mestrado no Programa de Pós-Graduação em Engenharia Urbana da Universidade Federal de São Carlos. Sob a orientação do professor Ricardo Siloto da Silva e novamente com o apoio financeiro da Fapesp, direcionei minha atenção, dessa vez, para uma única CN e sua relação com os conceitos de cidade-jardim. Com o título "Incorporação do ideário da garden-city inglesa na Urbanística Moderna Brasileira: Águas de São Pedro”, a dissertação defendeu a estância hidromineral paulista, projetada pelo engenheiro Jorge de Macedo Vieira em 1936, como a primeira cidade-jardim brasileira. A leitura histórico-conceitual das teorias urbanas do pós-Revolução Industrial, o entendimento da proposta howardiana de cidade ideal - inclusive com visitas a Letchworth e Welwyn Garden City, seus primeiros exemplos na Inglaterra -, a ressonância de tal tipo no Brasil e a desconstrução do projeto urbano de Águas de São Pedro proporcionaram tal confirmação.

Em 2005, após um primeiro contato com aquela que seria a orientadora da tese da qual este livro se origina, professora Sylvia Ficher, levei adiante meus estudos. 
A princípio, a proposta era ampliar o horizonte de pesquisa para todo o território nacional, tendo o século XX como período fulcral. Ao ingressar, em abril de 2006, no Programa de Pós-Graduação em Arquitetura e Urbanismo da Faculdade de Arquitetura e Urbanismo da Universidade de Brasília, a versão original foi nomeada: “Do traço, um Brasil urbano. Cidades novas planejadas: 1889 - 1988”. Vinculado à linha de pesquisa “Teoria, história e crítica”, o intuito era revelar um país de inúmeras cidades projetadas, distante de uma visão que, quase sempre, reconhece apenas quatro exemplares: Belo Horizonte, Goiânia, Brasília e Palmas, tendo como delimitação temporal a Proclamação da República - ou a origem de Belo Horizonte, 1893 - e a última Constituição Federal - ou a fundação de Palmas, 1989. Para isso, dividiu-se o período de cem anos em quatro, cujos exemplares mais significativos seriam analisados quanto à sua história, traçado urbano, projetista etc.

Todavia, tal proposta foi adiada em decorrência de dois episódios particulares. O primeiro refere-se às arguições feitas pelos professores Frederico de Holanda (UnB) e Marco Aurélio Andrade de Filgueiras Gomes (UFBA) na qualificação do projeto de tese, em abril de 2007. O segundo foi o estágio-doutorado realizado em Paris e Veneza entre agosto de 2007 e agosto de 2008.

Com a contribuição daqueles professores e as subsequentes orientações de Sylvia, identifiquei os obstáculos que, talvez, me impossibilitassem de concluir a tese em tempo hábil com a qualidade científica almejada. A ideia inicial se mostrava uma tarefa árdua, pois o número de CNs não parava de aumentar. ${ }^{1}$ Ademais, até então, os principais aspectos que caracterizam esse fenômeno urbanístico eram vagos - mesmo após anos de pesquisa direcionada.

Já a temporada em Paris, sob a tutela dos professores Monique Eleb e Philippe Panerai, e em Veneza, sob a supervisão da professora Donatella Calabi, propiciou a visita a outros exemplares, como Évry. Mas, fundamentalmente, colocou-me em

1 O projeto de pesquisa “Atlas de cidades novas no Brasil Republicano”, iniciado em 2014, vinculado ao grupo de pesquisa Paisagem, Projeto e Planejamento - Labeurbe (FAU-UnB) e à Cronologia do Pensamento Urbanístico (http://www.cronologiadourbanismo.ufba.br/) já identificou mais de 260 exemplares de cidades novas propositados em território nacional no século XX. 
contato com uma vasta e riquíssima bibliografia sobre CNs. Esse tête-à-tête com meu objeto de estudo fez novas portas se abrirem, e um mundo de informações se revelaram. Um momento de reflexão era necessário.

Ambas as experiências, qualificação e estágio-doutorado, após um período de sedimentação das inúmeras ideias e questionamentos que afloravam, permitiram-me chegar a um denominador comum para o fio condutor da tese. $\mathrm{O}$ fato de ter estudado e visitado inúmeras CNs, como: Brasília (DF), Belo Horizonte (MG), La Plata (Argentina), Santiago (Chile), Goiânia (GO), Andradina (SP), Guarujá (SP), Santos (SP), Adamantina (SP), Lucélia (SP), Votuporanga (SP), Águas de São Pedro (SP), Cosmorama (SP), Jales (SP), Oswaldo Cruz (SP), Panorama (SP), Aracaju (SE), Letchworth (Inglaterra), Welwyn Garden City (Inglaterra), Barcelona (Espanha), Marne-la-Vallée (França), Cergy-Pontoise (França), Cingapura (Cingapura), Tapiola (Finlândia) e mesmo Évry, não me habilitava como expert em CNs. Relatórios, artigos e dissertação, embora pertinentes quando escritos, não me atentaram a responder uma simples questão: o que são cidades novas?

Resumidamente, conceituo CNs como núcleos urbanos criados: 1) pelo desejo do poder público ou da iniciativa privada e concretizado em ações específicas; 2) para buscar atender, ao menos de início, a uma ou mais funções dominantes (administrativa, de colonização, ferroviária, de realocação, balneária, satélite etc.); 3) em um sítio previamente escolhido; 4) a partir de um projeto urbanístico; 5) por agente(s) definido(s) - eventualmente profissional(is) habilitado(s); e 6) em um limite temporal determinado, implicando, inclusive, em um momento de fundação razoavelmente preciso.

Se, num primeiro instante, este aparenta ser um tema simples e já resolvido, procurarei logo dissuadir o leitor. Pretendo mostrar que tais evidências preliminares camuflam algo mais denso, auspicioso de ser explorado.

Enfim, um questionamento pessoal transformado em roteiro para nossa viagem. 
Cidades novas é um livro que busca revelar os significados para esse fenômeno, um tipo à parte segundo a literatura especializada. Duas palavras que, unidas, simbolizam um fenômeno que acompanha o processo de urbanização desde sua origem. No plural, para abranger o conjunto de denominações encontradas em diferentes obras, como: “cidade nova planejada”; “cidade artificial”; “cidade protótipo”; “cidade de proveta”; “cidade construída de raiz”; “ville neuve”; “ville nouvelle”; "new town”; “cidade nova aberta”; “cidade nova fechada”; “cidade traçada”; “cidade planejada”; “cidade inventada”; “nova capital”; “nova vila”; “cidade concebida”; “cidade-sputnik”; “cidade ex nihilo”; “cidade plantada”; “introduced capital”; “cidade nascida radicalmente nova”; “cidade de nova fundação”; “cidade ideal”; "navyé goroda”; “new-town in-town”; "terra de Canaã”; “cidade concebida a priori”; “cidade regular”; “cidade surgida do nada”; "neue städte”; "twin towns”; “ciudad nueva”; “cidade de raiz”; “new communities”; “cidade concebida ex-novo”; “città nuova”; “cidade partindo do nada”; “cidades socialistas”; “cidade encomendada”; “cidade projetada”; “cidade-satélite”; “modoun eg gegida”; “città di fondazione”; “cidades de vontade”; “cidade-objeto”; “cidade fabricada”; “centro urbano novo”; “cidade por decreto”; “nuevos pueblos”; “cidade criada”; “新しい町”. Uma variedade de expressões para definir algo que, na essência, tem o mesmo sentido.

Veremos ao longo de nossa viagem que são termos empregados para caracterizar: a origem e a fundação de cidades; o desejo em criá-las; a função para que foram idealizadas; o tipo urbano adotado; a presença de um profissional responsável por planejá-las, planificá-las, projetá-las; sua localização estratégica etc. Termos empregados em diferentes línguas, épocas e situações. Termos empregados, a meu entender, com um único propósito: referir-se às CNs.

Distante do determinismo praticado por alguns autores em aplicar um único termo, tiro partido dos existentes, sem distinção nem exclusão, para revelar que são todos análogos. Seja qual for sua variação, cada expressão poderá ser utilizada no momento oportuno.

Assim intitulado, considero Cidades novas um estudo sistemático e generalista. 
Um enfoque sistemático é um enfoque teórico, já apontava George G. Simpson em 1961 (LÉVI-STRAUSS, 2002, p. 24-25). Consciente disso, busco, pela abordagem sistemática, “ordenar” as informações e fatos dispersos na literatura nacional e estrangeira a fim de estabelecer, teoricamente, parâmetros para a compreensão e entendimento das CNs.

Os títulos que tratam desse fenômeno urbanístico no Brasil são, em geral, estudos pontuais sobre modelos de fato construídos. Veja-se: Pierre Monbeig (1949) contextualiza a ocupação do oeste paulista e norte paranaense por meio da criação de dezenas de cidades; Roberta Marx Delson (1979) pontua as vilas de nova fundação no Brasil Colônia; Murillo Marx (1980) faz menção àquelas do período imperial (Teresina e Aracaju); Yves Bruand (1981) analisa apenas as cidades administrativas (Belo Horizonte, Goiânia e Brasília); Maria Cristina da Silva Leme (1999) organiza um capítulo sobre as novas capitais; Nestor Goulart Reis Filho (2000b) expõe a história do surgimento das cidades no país; Renato Leão Rego (2009) explora as cidades plantadas por capital privado no norte-paranaense. Mesmo trabalhos recentes, como aqueles encontrados nos anais de nossos principais eventos científicos sobre urbanismo, como os encontros nacionais da ANPUR e da ANPARQ e o Seminário da História da Cidade e do Urbanismo, apresentam somente estudos de casos ou abordagens tangenciais. Não há, portanto, uma efetiva discussão teórico-conceitual.

Já a ampla literatura estrangeira sobre o assunto ${ }^{2}$ trabalha a questão conceitual, porém a partir de exemplares realizados longe de nosso território e por meio de teorias descontextualizadas de nossa realidade.

2 Citam-se, dentre inúmeros, os trabalhos: The ideal city: from Plato to Howard (LANG, 1952); Toward new towns for America (STEIN, 1957); L'idea della Città Giardino (GIORDANO, 1962); New towns of middle ages (BERESFORD, 1967); Les cités de l'avenir (RAGON, 1967); Les villes nouvelles e Les villes nouvelles en France (MERLIN, 1969a e 1991); New towns in America: the design and development process (BAILEY, 1973); New towns. Their origins, achievements and progress (OSBORN \& WHITTICK, 1977); New towns revisited (HALL, 1983); Les villes nouvelles dans le monde (CHALINE, 1985); Villes neuves et villes nouvelles (PANERAI et al, 1986); Ville nouvelle (CHOAY, 1988); Villes nouvelles et villes traditionelles (HAUMONT et al, 1999); Planning twentieth century capital cities (GORDON, 2006). Somam-se a esses referenciais as instituições estrangeiras criadas especialmente para discutir CNs, como o International New Towns Institute (INTI) e a International New Towns Association (INTA), ambas sediadas na Holanda. 
Consciente da ausência de obras conceituais no cenário nacional e, igualmente, de teorias contextualizadas à nossa realidade em âmbito estrangeiro, resolvi aceitar o desafio colocado pelo professor Carlos Roberto M. de Andrade em seu artigo “A construção historiográfica da cidade e do urbanismo moderno no Brasil: o caso das cidades novas planejadas” (PINHEIRO; GOMES, 2005, p. 73-90), que instiga pesquisadores a ampliar a abordagem ainda restrita sobre o assunto. Assim, dispus-me a construir uma teoria made in Brazil sobre CNs.

No mais, Cidades novas é também um estudo generalista, ao "recompor seus fragmentos”, partes dispersas encontradas na literatura, numa "imagem ordenada e significativa”, como conceitua Lewis Mumford (1969, p. 5).

Imaginemos o quebra-cabeça. Sua montagem pode ser considerada um processo de ordenamento dos fragmentos de uma única imagem, dispersos aleatoriamente no espaço. Para construir a imagem, o jogador deverá passar por uma longa fase de tentativas (erros e acertos), em que a perplexidade, a multiplicidade e a similaridade entre as peças dificultarão seu objetivo. Conforme passa o tempo, o jogador estabelece um entendimento maior sobre sua figura, o que torna suas ações cada vez mais rápidas e certeiras. Ao final, a imagem se faz presente, revelando, além de sua totalidade, os detalhes camuflados pela desintegração inicial, mesmo que não se tenha à disposição todas as peças.

Se pensarmos o presente estudo como o ato de construir a imagem ou o significado das CNs a partir de fragmentos soltos no tempo e no espaço, podemos aproximá-lo da fórmula do quebra-cabeça; porém, sem a ideia da imagem final a ser formada. As peças desse jogo assumem o caráter de fatos, dados e relatos que são disponibilizados por meio de pesquisas, análises e levantamentos. O jogador se transforma em pesquisador. Diferentemente da racionalidade colocada no quebra-cabeça, com número exato de peças e local específico para cada uma, a pesquisa se depara com incertezas, variações e imprecisões impostas pelos materiais encontrados. 
Nos estudos teóricos, um mesmo objeto pode ser construído em várias versões, como Manfredo Tafuri pontuou na introdução de seu livro La esfera y el laberinto (1984). A multiplicidade de fatos acolhidos por um intérprete pode ser agrupada conforme o repertório individual e o contexto (espacial e temporal) onde este se situa. Cada intérprete será responsável pela criação de um objeto único, porém efêmero, que será reformulado pelas variações temporais, pelo acréscimo de peças recém-descobertas e pelas diferentes manipulações realizadas por outros agentes. Sendo assim, a diversidade de resultados proporciona uma construção teórica que, por sobreposições e contraposições, tende a enriquecer a apreensão de um mesmo objeto.

Desse modo, pretendo contribuir para a urbanística brasileira ao somar esta pesquisa a outras do gênero. Com o objetivo central de construir os parâmetros necessários para a conceituação de CNs, por análises históricas, discussões conceituais e estudos de casos, esta pesquisa foi buscar as peças necessárias para a construção desta versão de um quebra-cabeça provisório. A manipulação da documentação levantada no Brasil e no exterior, ${ }^{3}$ que, embora tenha sistematizado determinado número de peças, pode ter deixado outras de fora e, num novo desdobramento, poderão ser encaixadas, dando ao objeto analisado uma nova configuração.

Assim é Cidades novas, um estudo sistemático, generalista, contextual, pessoal e efêmero. Um trabalho constituído na história do urbanismo, tendo como linha condutora dezenas de exemplares de CNs.

Lançar mão da história para compreender as CNs sob o ponto de vista urbanístico permite-nos entender sua configuração atual, criticá-las e projetar seu desenvolvimento a partir de um conhecimento contemporâneo. A pesquisa histórica não se restringe apenas em entender o processo de desenvolvimento de uma cidade, mas pode trazer à tona exemplos urbanísticos que nos auxiliam em seu planejamento.

Saliento que, embora uma CN tenha um marco temporal preciso - sua fundação -, isso não significa que sua história se inicie somente a partir desse ponto. Um plano

3 Acessada em pesquisa no Centre de Documentation de l’Urbanisme - CDU, em La Defénse (França), e nas bibliotecas do Istituto Universitario di Architettura di Venezia (Itália). 
urbano é a expressão de toda a história de uma cidade e não o flash do momento de sua criação ou os frames durante sua evolução. Com base nos pensamentos de Fernand Braudel, em sua obra Écrits sur l'histoire (1969), a história das cidades deve ser interpretada não como um episódio eventual, mas como um episódio de longa duração. A cidade sem passado é irreal, mesmo tendo sido gerada num curto espaço de tempo. Sabe-se que, para qualquer nascimento, existe um estágio fetal e todos os antecedentes que levaram à sua concepção: desejo, função, escolha do sítio etc. Nossa busca, portanto, irá preceder a materialidade física, encontrando vestígios - desejos e necessidades - que levaram à sua criação.

Quanto ao período estudado, iremos transitar dos primeiros núcleos urbanos planejados na história, o que nos remete à Antiguidade, até os exemplares mais recentes - diferentemente da visão limitada de Claude Chaline, em seu livro Les villes nouvelles dans le monde (1985), que situa a origem das CNs na teoria formulada pelo inglês Ebenezer Howard em suas cidades-jardins de amanhã (1898). Também não iremos nos ater a uma narração linear cronológica dos fatos urbanos. ${ }^{4}$ Não se trata, pois, de uma exposição histórica contínua do urbanismo de CNs. Os casos aparecerão pinçados de um determinado momento histórico e conforme a necessidade de materializar uma ideia, um conceito, um tipo urbanístico. ${ }^{5}$ Enfim, um estudo histórico guiado pelo estudo urbanístico.

Ao analisar o espaço físico das cidades, emergem, dos planos, detalhes reveladores: diferenças, oposições, rupturas. São figuras, são desenhos, são peças de um

4 Como nos clássicos: L'urbanistica e l'avvenire della città, de Giuseppe Samonà (1959); The city in history, de Lewis Mumford (1961); L'urbanisme, utopies et réalités, de Françoise Choay (1965); Evolução urbana no Brasil (1500/1720), de Nestor Goulart Reis Filho (1968); Storia dela Città, de Leonardo Benevolo (1976); History of urban form, de Anthony Morris (1979); Cidade brasileira, de Murillo Marx (1980); Historia del urbanismo, de Paolo Sica (1981); e Cities of tomorrow, de Peter Hall (1988); The seduction of place, de Joseph Rykwert (2004); e Storia dela città, de Donatella Calabi (2001 e 2005).

5 Tal qual fizeram: Carlo Aymonino em El significado de las ciudades (1981); Spiro Kostof em The city shaped (1991); Philippe Panerai em Analyse urbaine (1999); Maria Cristina da Silva Leme em Urbanismo no Brasil, 1895 - 1965 (1999); José María Ordeig Corsini em Diseño urbano y pensamiento contemporáneo (2004); Pedro Paulino Guimarães em Configuração urbana - evolução, avaliação, planejamento e urbanização (2004); entre outros. 
quebra-cabeça que nos permitem, parafraseando Castex et al. (1980, p. 3), recortar os índices, de um conhecimento adquirido, de uma capacidade de reconhecer as entidades que já vimos aplicadas em outros lugares, agrupá-las, opô-las, de modo a clarear uma questão, a produzir um senso, a ordenar simplesmente os fatos.

No anseio de compreender uma cidade antiga e, por exemplo, o caso particular de uma cidade criada ex nihilo - do nada -, o emprego da análise urbanística é indispensável. Essa análise começa por examinar o sítio, o local exato onde se fez a implantação inicial, e a situação, a posição da cidade em sua região. Posteriormente, passa-se à análise do tecido urbano e da relação entre o parcelamento e a via, a importância ou a ausência de espaços públicos etc.

O estudo da forma urbana nos coloca frente a frente com os diferentes tipos de traçado e tecido adotados conforme o desejo, a necessidade, o sítio, o repertório do projetista à época. Consoante a trabalhos referenciais sobre morfologia urbana, ${ }^{6}$ intento, sempre que possível, estabelecer uma relação entre a configuração do traçado das CNs e os motivos de sua adoção, geralmente interligados a um dos parâmetros que compõem as CNs.

Diante dos instrumentos, manuais e procedimentos postos, cabe agora revelar ao leitor a estrutura desta obra a fim de posicioná-lo na jornada a ser empreitada.

Como auxílio a esta expedição, estruturei um roteiro da jornada por este livro com uma estação de partida, uma conexão e seis paradas, cada qual introduzida por uma ou um conjunto de CNs brasileiras, escolhidas por afinidade com os temas abordados e pinçadas da história republicana brasileira. Uma estação de partida, uma conexão mais teórica - contextualização e conceituação - e seis paradas mais ilustrativas - atributos inerentes às CNs -, visando a facilitar o entendimento sobre a teorização de CNs.

6 Sobretudo: À propos de la morphologie urbaine, de Françoise Choay e Pierre Merlin (1986); A cidade como um jogo de cartas, de Carlos Nelson Ferreira dos Santos (1988); Introdução ao desenho urbano no processo de planejamento, de Vicente Del Rio (1990); La qualité de la forme urbaine: problématique et enjeux, de Albert Levy (1992); Morfologia urbana e desenho da cidade, de José M. Ressano Garcia Lamas (1993); e Analyse urbaine, de Philippe Panerai (1999). 
Na estação de partida - contexto -, procuro posicionar as CNs no urbanismo, distinguindo-as de outros produtos urbanos. Também apresento o caráter utópico que envolve o objeto em foco e a possibilidade de transformar sonho em realidade por meio da idealização e da criação. Já direcionando os estudos, na conexão dou atenção aos conceitos que compõem esse fenômeno urbano. A partir de uma revisão na literatura sobre os já existentes e a discussão sobre as variações terminológicas utilizadas, realizo a minha própria definição, entendendo CNs como um corpo formado por partes diversas, porém afins.

Percurso inicial cumprido, foco, em cada parada, da primeira à sexta, os seis atributos inerentes às CNs. Inicio pelo capítulo 1 - Desejo em se criar uma CN e os agentes envolvidos, que é interligado ao capítulo 2 - Necessidade de sua criação e a função preliminar para qual foi idealizada. Em seguida, passo ao capítulo 3 - Local e a escolha do sítio e sua posição estratégica, ao capítulo 4 Profissional e o envolvimento de projetistas de formação diversas, ao capítulo 5 - Projeto implantado e suas formas: o traçado e o tecido e, finalmente, chego ao capítulo 6 - Tempo peculiar a essas cidades.

É por esse roteiro, ilustrado a partir de algumas imagens selecionadas da tese - preciosa e delicada arte feita pela arquiteta e urbanista Arielle Cristina Martins -, que pretendo guiá-los, da estação de partida, com conexão e paradas estratégicas, a fim de refletir e questionar os pensamentos, os conceitos, as ideias, visando à formulação de uma proposta teórica sobre CNs. 